\title{
Orbital cyst due to Histoplasma duboisii
}

\author{
R. K. BANSAL, A. V. SUSEELAN, AND H. C. GUGNANI \\ From the Department of Ophthalmology, Morbid Anatomy, and Microbiology, University of Nigeria \\ Teaching Hospital, Enugu, Nigeria
}

SUMmaRY A cystic swelling in the orbit due to Histoplasma duboisii, clinically thought to be a dermoid cyst, is described.

Histoplasmosis due to Histoplasma duboisii, known as African histoplasmosis, may occur localised as a solitary nodule, as a bone lesion, or in disseminated form involving skin, subcutaneous lymph nodes, bones and joints and abdominal viscera, and rarely the lungs (Vanbreuseghem, 1953, 1956).

Intraocular involvement has been described in some cases of the classical American histoplasmosis due to Histoplasma capsulatum (Krause and Hopkins, 1951; Van Metre and Maumenee, 1964; Schlaegel and Kenney, 1966). So far only one case has been reported of acute infection of lacrimal gland and adjacent parts of frontal and zygomatic bones caused by $H$. duboisii (Olurin et al., 1969). The present communication reports another case of orbital histoplasmosis due to $H$. duboisii, presenting as a silent solitary cystic swelling with erosion of supraorbital margin.

\section{Case report}

A 20-year-old Igbo welder presented with a swelling in the right supraorbital region of probably two months' history. It started as a small nodule, painless, and without any history of injury.

On examination there was a localised, slightly firm, well defined cystic swelling $(2 \times 2 \mathrm{~cm})$. It was not tender, and was slightly mobile but with skin moving freely over it. The upper border of swelling appeared to erode the supraorbital margin. The posterior wall was not palpable. The visual acuity was normal, right eye $20 / 15$, left eye $20 / 15$. There was no other ocular lesion. $X$-ray examination of orbit showed erosion of the supraorbital margin. No cutaneous lesion was found. Systemic examination and $x$-ray of chest were normal. On clinical assessment it was provisionally diagnosed as a case of dermoid cyst.

Address for reprints: Dr R. K. Bansal, Department of Ophthalmology, Morbid Anatomy and Microbiology, University of Nigeria Teaching Hospital, Enugu, Nigeria

\section{Surgery}

A supraorbital incision was made and a very well defined cystic swelling was exposed. The wall of the swelling was seen to be fixed at the upper border and deep surface. The cyst ruptured, and thick blood-stained pus was evacuated. The wall of the cyst was removed in pieces and sent for histological examination.

\section{Histology}

The cyst wall was devoid of any epithelial lining but appeared to be composed in part of fibro-collagenous tissue. Around the cyst wall numerous yeast cells (7 to $15 \mu \mathrm{m}$ in diameter) typical of Histoplasma duboisii (Figs. 1, 2) were observed within giant cells

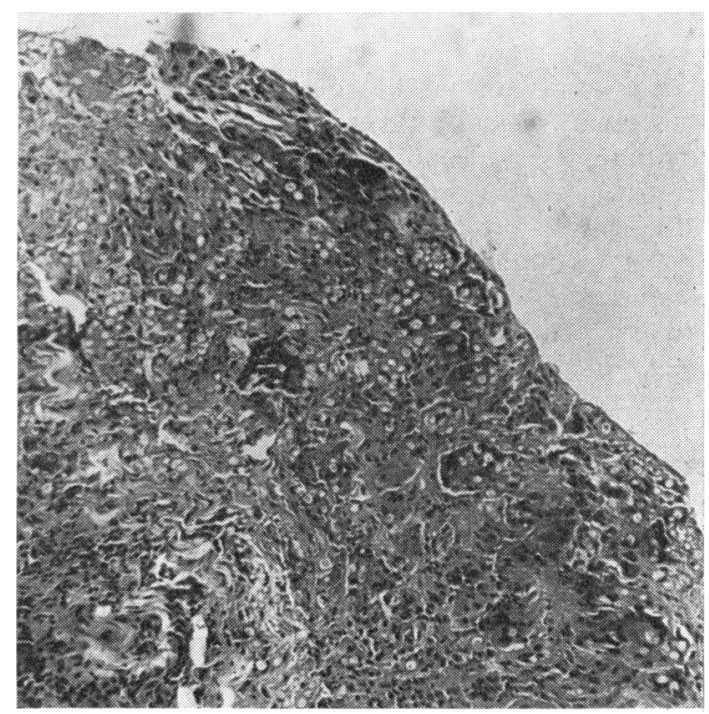

Fig. 1 Low magnification $\times 140$ 


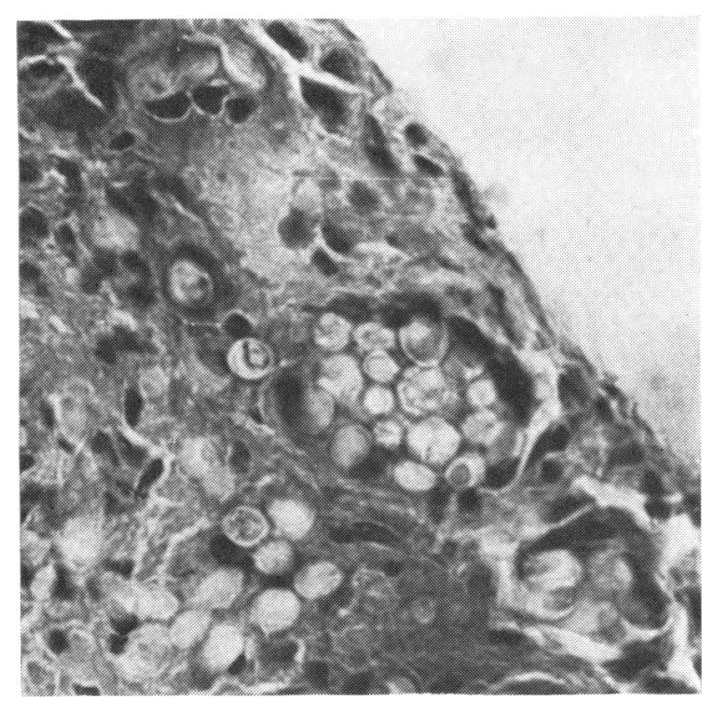

Fig. 3 High magnification $\times 475$. Section through the cyst showing $\mathrm{H}$. duboisii cell within and outside giant cell. The cyst wall is devoid of any epithelial lining

as well as occurring extracellularly along with macrophages, plasma cells, and lymphocytes.

\section{Discussion}

Ocular histoplasmosis is mainly caused by Histoplasma capsulatum and usually presents in the form of uveitis or chorioretinitis. Another form of histoplasmosis has now been recognised caused by $H$. duboisii, which presents clinically and histologically in a different way. Previously only one case of orbital histoplasmosis due to $H$. duboisii has been described in a young girl as a localised acute inflammation (Olurin et al., 1969). In the present case there was no evidence of ocular inflammation at any stage.

\section{References}

Krause, A. C., and Hopkins, W. G. (1951). American Journal of Ophthalmology, 34, 564.

Olurin, O., Lucas, A. O., and Oyediran, A. B. O. (1969). American Journal of Ophthalmology, 68, 14.

Schlaegel, T. F., Jr., and Kenney, D. (1966). American Journal of Ophthalmology, 62, 454.

Vanbreuseghem, R. (1953). Mycologia, 45, 803.

Vanbreuseghem, R., Dubois, Brutsaert, P., and Janssens, P. G. (1953). Annales de la Société belge de médicine, 33, 171.

Vanbreuseghem, R. (1956). Mycologia, 48, 264.

Van Metre, T. E., and Maumenee, A. E. (1964). Archives of Ophthalmology, 71, 314. 